\title{
Investigation of Wickless Heat Pipe Performance Filled With R134a
}

\author{
Huthaifa Ahmed Abed ${ }^{1 *}$, Majid H. Majeed ${ }^{2}$ and Ahmad Q. Mohammad ${ }^{3}$ \\ 1. Technical Engineering Collage / the Midland Technical University/ Baghdad- Iraq. \\ 2 . Prof.dr. Technical Engineering Collage / the Midland Technical University/ Baghdad- Iraq. \\ ${ }^{3}$. Prof.dr. Technical Engineering Collage / the Midland Technical University/ Baghdad- Iraq. \\ 1e31440@gmail.com,2dr.ahmed56@yahoo.com, ${ }^{3}$ drmajidhmm@gmail.com \\ *Corresponding Author: e31440@gmail.com
}

\begin{abstract}
The wickless heat pipe (theroosyphon) is ordinate of three divisions the condenser, evaporator and insulated region (adiabatic region). In this work, the condenser and evaporator regions are made of copper tube with a length of $300 \mathrm{~mm}$, for each an exterior diameter of $28.2 \mathrm{~mm}$ and an interior diameter of $26.4 \mathrm{~mm}$. While the insulated region has a length of $400 \mathrm{~mm}$ and an exterior diameter of 28.2 $\mathrm{mm}$. The evaporator region of the heat pipe bounded by a coiled heat source that represented the heat source. The condenser is encapsulated in a plastic cylinder to accommodate the flow of the cooling water. Thermosyphon has been filled by R134a working fluid. The effect of heat input, filling ratio and sink temperature were all tested and measurement. The results showed that the heat transfer performance increases when the applied energy to the evaporator increases while the total heat transfer efficiency of the heat pipe increases the gradient temperature between the medium of the evaporator and the condenser increases. The optimum fill rate is 119 $\%$ (250g), the sink temperature is $20^{\circ} \mathrm{C}$, and it has been found to be suitable for optimum heat pipe performance.
\end{abstract}

\section{Keywords: Wickless heat pipe, effect of filling ratio, RI34a}

\section{INTRODUCTION}

Energy saving is increasingly becoming significant as the cost effective of fuel utilizes. So, the heat pipe and the closed two-phase thermosyphon are proved particularly effective tools in the heat transfer industry. The basic idea of the heat pipe was suggested by R.S.Gaugler in 1943. In 1946, G. Grover reinvented the concept of heat pipe at Los Alamos National Laboratories. Because of this invention, interest in heat pipes and their applications has increased [1]. Many investigations have been established to analyze the heat transport performance of a thermosyphon and many have looked into different factors that influence its performance. Majid, et.al (2013)[2] tested the heat pipe that made to drive with R-134a, they Found that increasing filling ratio tends to reduce heat pipe temperature for certain value then it goes up again. Majid and Osamah (2016)[3] studied the effect of the wick assembly material (Copper and Bronze) sieves of porous material on heat pipe duty filled with R134a, they prevail that the thermal diffusivity has no significance on the heat pipe efficiency. The impact of working distillation fluid amount on concert of heat pipe was investigating by Majid, et.al (2013)[4]. This study was carried at different filling ratio and heat input. The results show the optimal water charging ratio is $87 \%$ of the wick volume, where recognized in 
terms of inferior temperature gradient between evaporator and condenser, minor heat transport resistance and higher heat transfer performance. Amer and Majid (2018)[5] studied the duty of parallel heat pipe occupied with R134-a. They investeged that when the heat input increased to evaporator, the thermal resistance decreases while the heat performance increased. The results also indicated the gradient between mean temperature of condenser and evaporator was rises likewise the energy transferred increases. Basil N, et.al (2019)[6] studied the flat plate type solar heater with thermosyphon experimentally. The experimental system consists of solar irradiation simulator, flat plate solar collector heater, heat pipe (wickless), heat exchanger equipment and measurement devices. Their experimental consequences showed the efficiency of solar collector with warped evaporator higher than other kinds of evaporator. K.S.Ong, and Md.Haider-E-Alahi (2003)[7] investigated the heat transfer duty of thermosyphon heat pipe occupied with R-134a. It is found that the increased amount of cold water around condenser section, temperature gradient between condenser and evaporator section and filling ratio lead to an increase the performance of thermosyphon . Thanaphol Sukchana, and Chaiyun Jaiboonma (2013) [8] investigated the impact of insulated length and filling ratio on performance of heat pipe filled with R134a . It is found that the thermal duty of heat pipe effect by charging ratios more than the insulation length.. Grzegorz Gorecki, (2018)[9] studied thermal performance of multi-phase thermosyphon heat pipe filled with R407C, R404A and R134a. The consequences prevailed that using R134a and R404A as refrigerants heat transfer rates are the highest. Abdelrahim Abusafa and Aysar Yasin (2020)[10] they investigated The impact of heat duty per unit area and the working fluid pressure on the evaporator sections heat transfer performance. The consequences showed that the heat transport performance increases by rising the heat duty by area unit on the evaporator or by reduction of the interior pressure.

\section{Experimental Rig Descrbtion}

The experimental sets up as shown in Fig. 1. The Thermosyphon heat pipe shell was made of a (28.2)mm outer diameter and $26.4 \mathrm{~mm}$ inner diameter with $(1 \mathrm{~m})$ long copper pipe. The pipe was welding with two flanges concentrically at each of its ends, sealed with $O$ rubber ring to brass plates by bolts. These two flanges and plates were used to fix the pressure gage on the condenser and evaporator ends and charging-discharging valve to the condenser side end. The condenser region was of $300 \mathrm{~mm}$ long. It was covered with a (PVC) tube with inner diameter of $64.2 \mathrm{~mm}$. It serviced with a condenser region as a double pipe heat exchanger, in which heat transfer from the working fluid (R134a) and the water flowed in the outer shell. The water enters the heat exchanger with a cretin mass flow rate to gain the latent heat lost from the refrigerant to convert it to a liquid phase. The rate of heat lost into the condenser is calculated by the following relation

$$
\mathrm{Q}_{\mathrm{c}}=\dot{\mathrm{m}}_{\mathrm{w}} \mathrm{Cp}_{\mathrm{w}}\left(\mathrm{T}_{\mathrm{wo}-} \mathrm{T}_{\mathrm{wi}}\right)
$$

Where $\dot{m}_{w}$ is the cooling water mass flow rate through the condenser in $\mathrm{kg} / \mathrm{s} . \mathrm{Cp}_{\mathrm{w}}$ is the specific heat of water which is assumed constant and equal $(4.180 \mathrm{~kJ} / \mathrm{kg} . \mathrm{K})$ and $\left(\mathrm{T}_{\mathrm{wo}}, \mathrm{T}_{\mathrm{wi}}\right)$ are the inlet and outlet temperature of water to condenser respectively. 


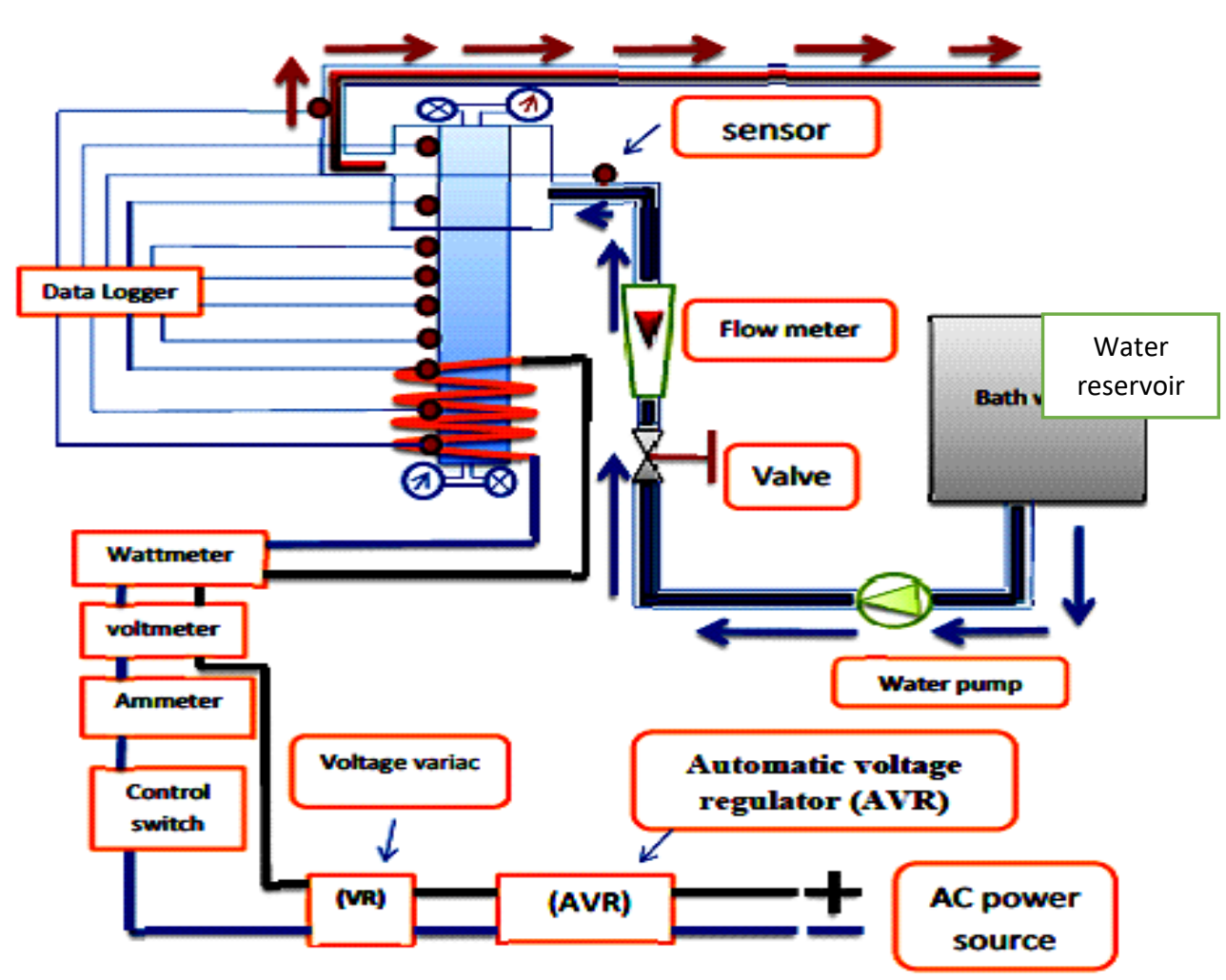

Figure 1. Schematic of Experimental Set Up

An electrical resistance coil was used to cover the evaporator region on the other side of the heat pipe. The electrical coil heats the working fluid, causing it evaporate .

A wattmeter was used to measure the heat generated by this coil, which was denoted as $\dot{Q}_{\mathrm{E}}$. Some of the heat generated from the coil is conducted to the condenser through the pipe wall and transfer to the surroundings due to temperature gradient by convection and radiation. This amount of heat lost is denoted $\dot{Q}_{\text {Loss }}$. In this research the quantity of $\dot{Q}_{\text {Loss }}$ is assumed to be the sum of convection and radiation heat losses. The heat losses by convection and radiation was calculated by using the conventional heat transfer relations of convection and radiation. Then the net heat that transferred to the working fluid in the evaporator $\left(\dot{Q}_{\mathrm{e}}\right)$ is calculated by the following equation:

$\dot{\mathrm{Q}}_{\mathrm{e}}=\dot{\mathrm{Q}}_{\mathrm{E}}-\dot{\mathrm{Q}}_{\mathrm{Loss}}$

The temperature of the inlet and outlet water was also considered to have an impact on the heat pipe's performance. The sink temperature is defined as the average of the inlet and outlet temperatures, denoted as $\left(\mathrm{T}_{\mathrm{S}}\right)$.

$\dot{\mathrm{Q}}_{\mathrm{Loss}}=\mathrm{A}_{\mathrm{e}} \mathrm{h}\left(\mathrm{T}_{\mathrm{s}-} \mathrm{T}_{\mathrm{a}}\right)$

Where $(\mathrm{h})$ is the (convection +radiation) heat transfer performance . $\left(\mathrm{T}_{\mathrm{S}}\right)$ is surface temperature and $\left(\mathrm{T}_{\mathrm{a}}\right)$ is the ambient temperature and $A_{e}$ is the outer surface of evaporator .

\section{Results:}

The readings that taken from experimental rig are evaporation heat duty $(\mathrm{P})$, condensation sink temperature (Ts) and Freon mass using R134a . The results concentrated on temperature profiles through heat pipe wall, thermal resistance and over all heat transfer performance. The 
results exhibit the trends of free convection and conductive heat transfer which is formed by mean of evaporation- condensation processes.

\subsection{The Effect Condensation Sink Temperature on Temperature Profile}

The effect of sink temperature (temperature of water entering the condenser) is studied on the profile of temperature along the heat pipe. Figure (2) shows that the profile of temperature along the heat pipe for different values of sink temperature and constant heat input $(\mathrm{QE}=40 \mathrm{~W})$ and mass of refrigerant equal to $(400 \mathrm{~g})$.It is noted that the wall temperatures of the condenser and evaporator sections will increase when the sink temperature increases. It is because of the condensing temperature is raised so that the temperature along heat pipe is also increase.

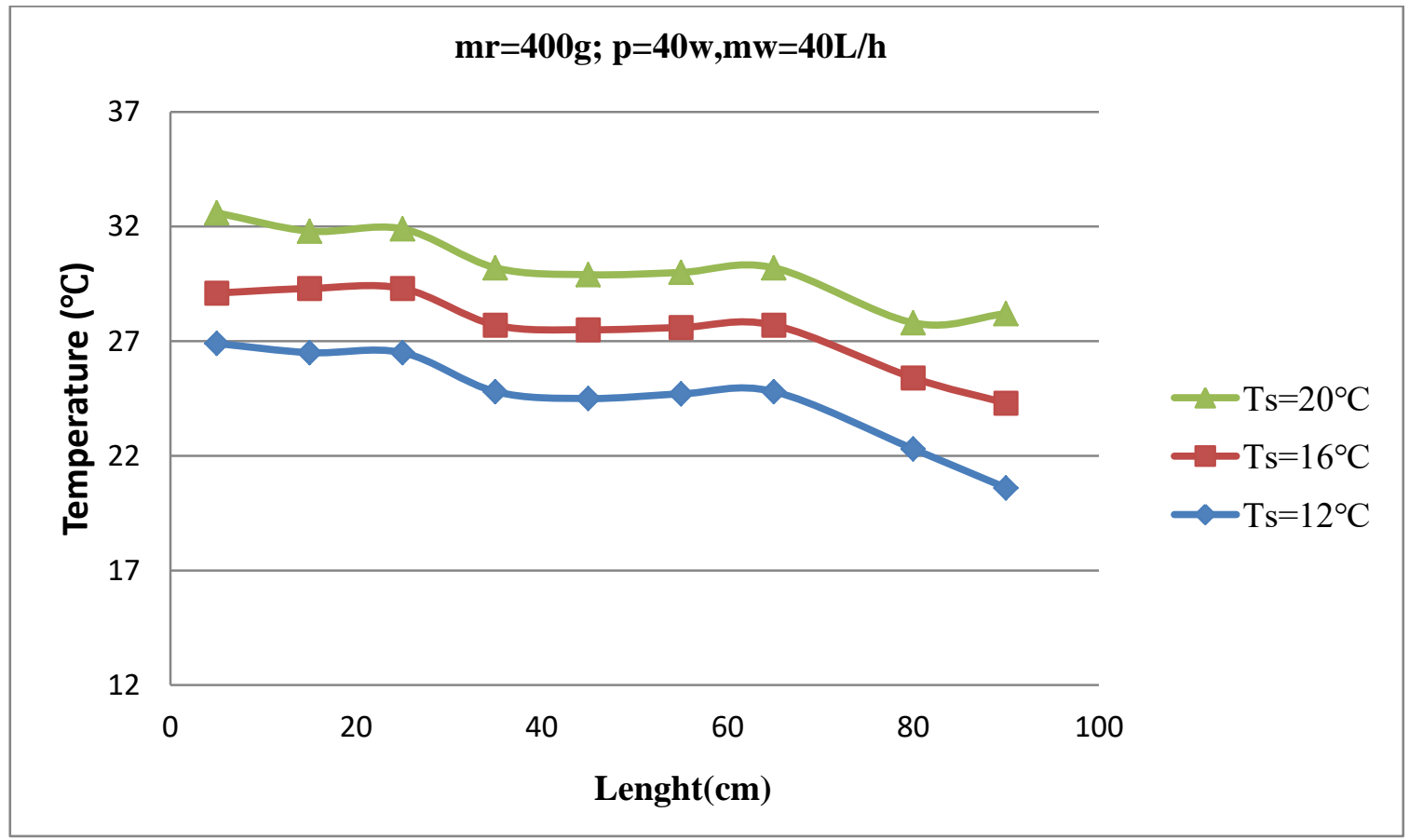

Figure 2: Heat Pipe Wall Temperature Profile at Various Sink Temperatures at Heat Duty of 40W And Mr=400

\subsection{Effect of Heat duty Input on Temperature Gradient}

The temperature gradient between the evaporator and condenser increases at constant sink temperature by increasing the heat duty input as shown in Figures (3-5). These figures also show the increase in the heat duty input within the temperature gradient between the condenser and the evaporator, linearly increases when the inside water temperature increases until it stabilizes at $20^{\circ} \mathrm{C}$ of water inlet temperature. That occurred because as the heat input to the evaporator increased the temperature of working fluid and also the pressure increased and saturated temperature raised so the temperature so the temperature along the heat pipe increased also.

As shown in figure (6), temperature gradient vs. heat duty for various sink temperature. The temperature difference has unordinary behavior for various sink temperature. The temperature difference increase by decreasing the sink temperature with non-ordinary behavior for $\mathrm{Ts}=16^{\circ} \mathrm{C}$. The thermal residence time between the fluid particles which rise due to evaporative action and those drops due to condensation action will increase 
by increasing sink temperature and vice versa which effect on heat transfer coefficient with corresponding to heat input.

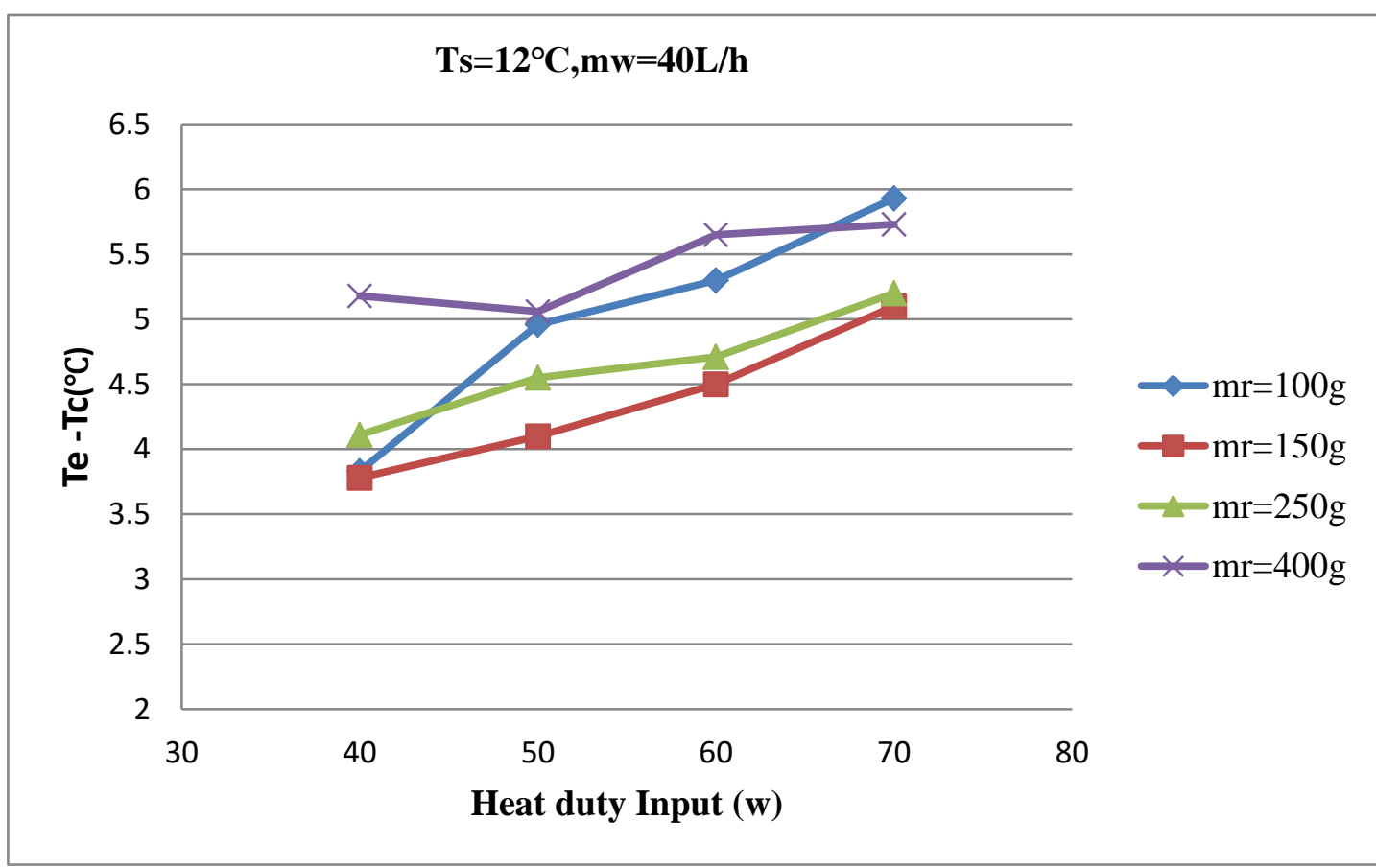

Figure 3: Effect of Input Heat Duty on Gradient in Temperature Between Evaporator And Condenser

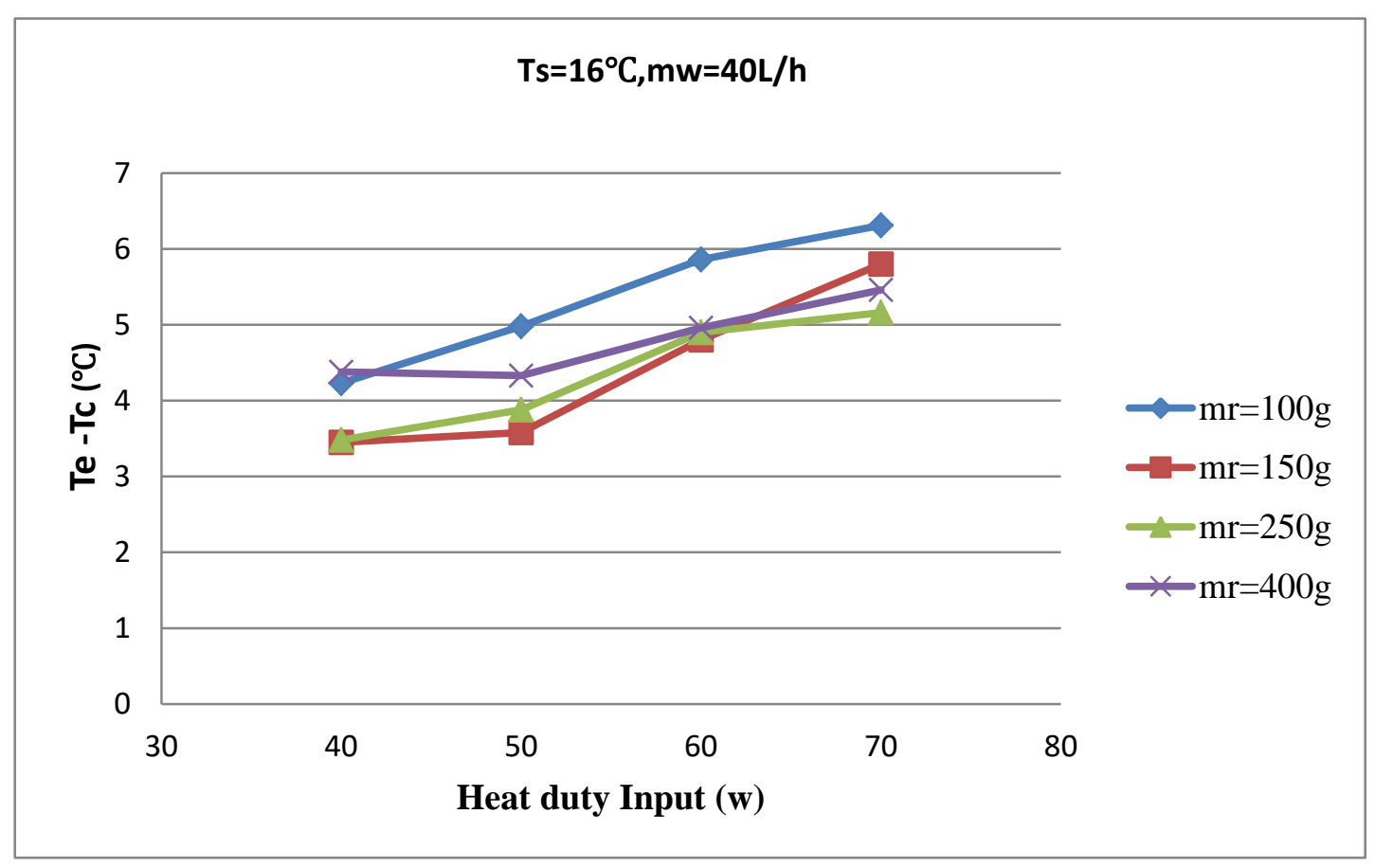

Figure 4: Effect of Input Heat Duty on Gradient in Temperature Between Evaporator And Condenser 


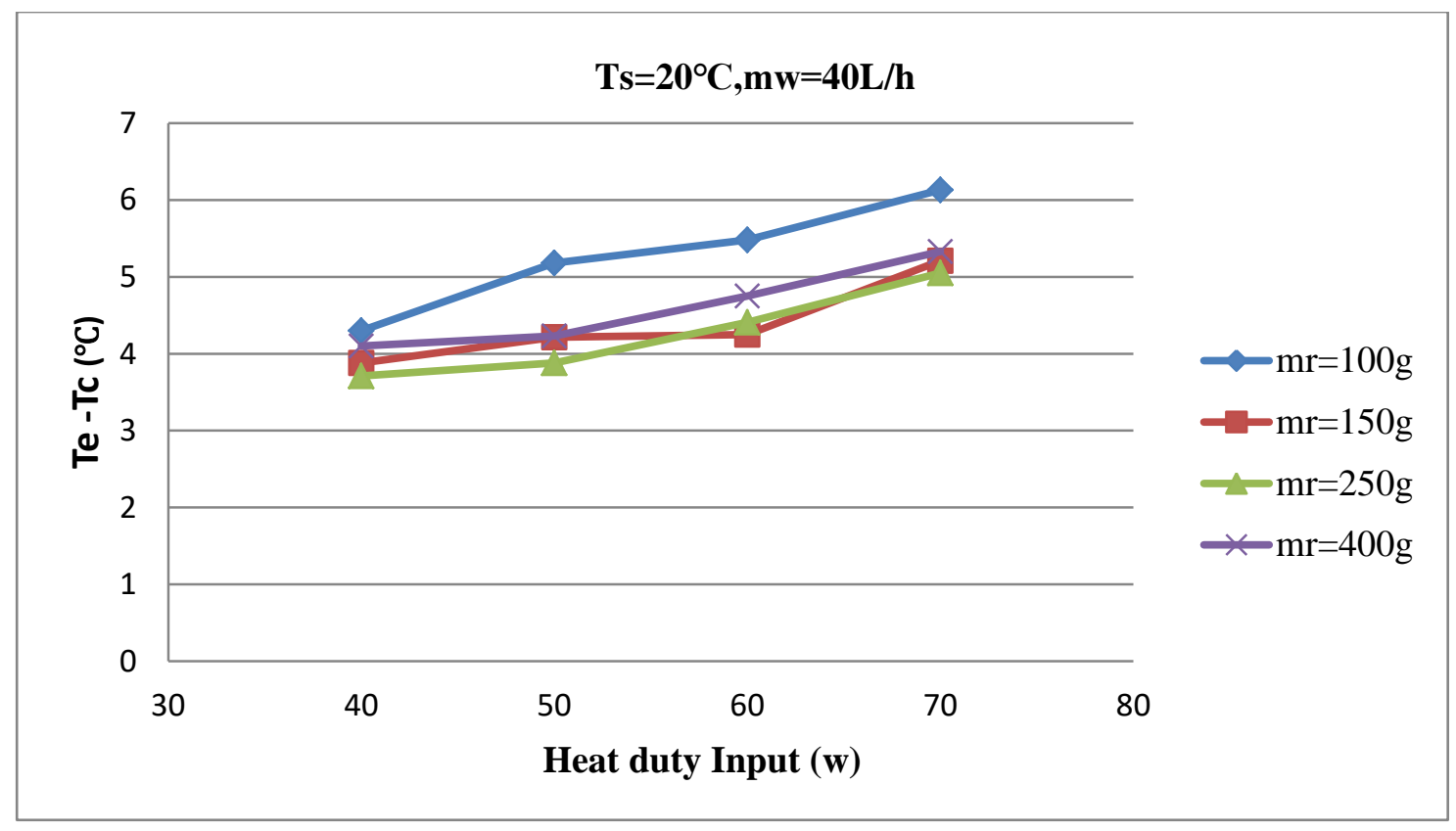

Figure 5: Effect of Input Heat Duty on Gradient in Temperature Between Evaporator And Condenser

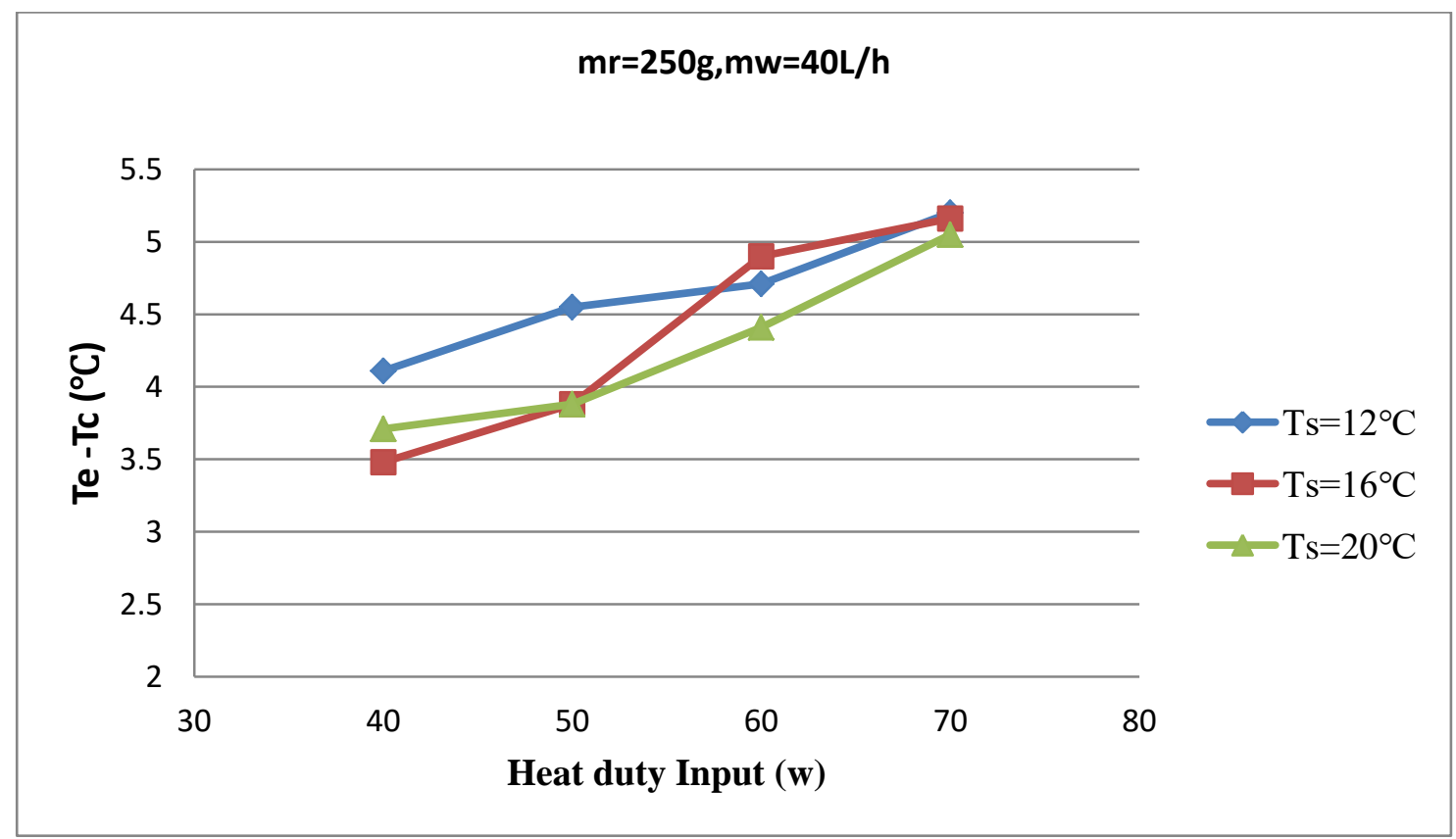

Figure 6: Effect of Input Heat Duty on Gradient in Temperature Between Evaporator And Condenser

\subsection{Effect of Heat duty Input on Thermal Resistance}

Figures (7-8) show the relation between thermal resistance and heat input at three different sink temperatures $(12,16,20)$. It is clearly showed that at $20^{\circ} \mathrm{C}$ the heat pipe thermal resistance decreases compared to that of 12 ,this because as the water temperature of 
cooling water increased the ability of water to absorb heat due to the temperature gradient is less .

Figures (9-11) shows the variations in heat transfer rate with heat input for different masses of R-134a . It's clear showed that the maximum heat transfer rate occurs at masses between $150-250 \mathrm{~g}$.

The thermal resistance of heat transfer in the heat pipe is calculated from the following equation.

$\mathrm{R}_{\mathrm{th}}=\frac{\left(\mathrm{T}_{\mathrm{e}}-\mathrm{T}_{\mathrm{c}}\right)}{\mathrm{Q}_{\mathrm{e}}}$

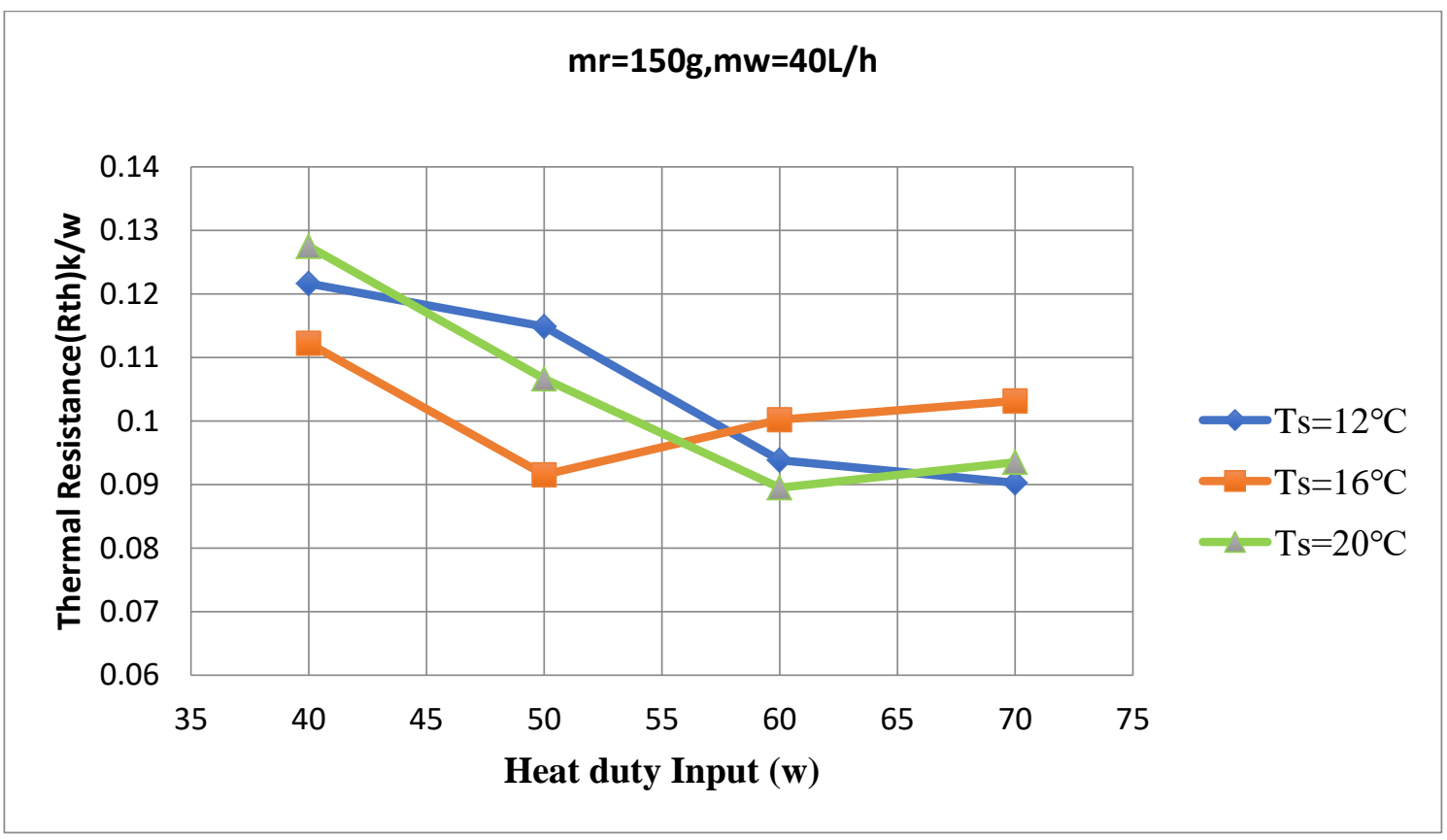

Figure 7: Effect of Input Heat Duty on Thermal Resistance at Different Sink Temperatures at $\mathrm{Mr}=150 \mathrm{~g}$ 


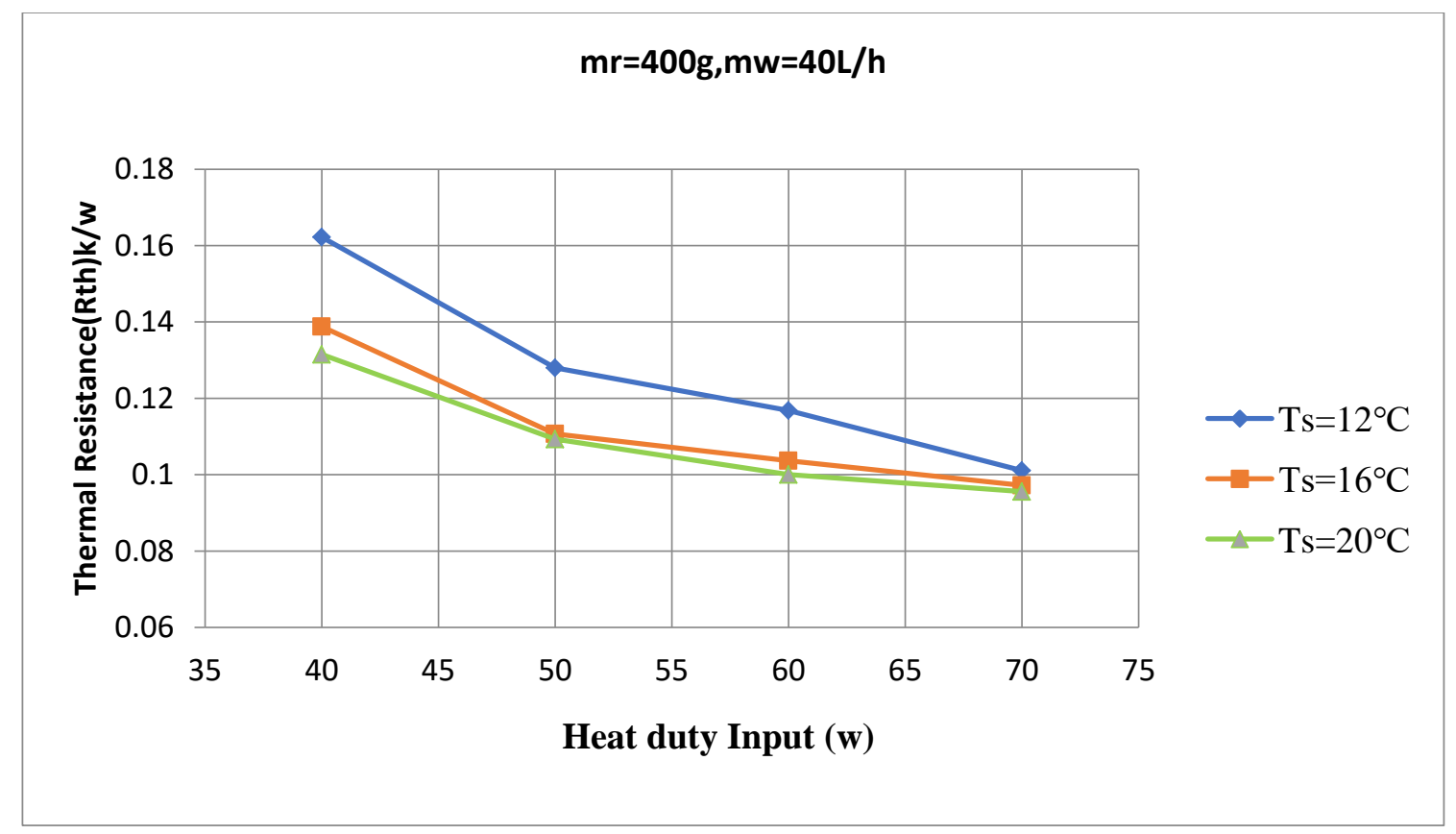

Figure 8: Effect of Input Heat Duty on Thermal Resistance at Different Sink Temperatures at $\mathrm{Mr}=\mathbf{4 0 0 \mathrm { g }}$

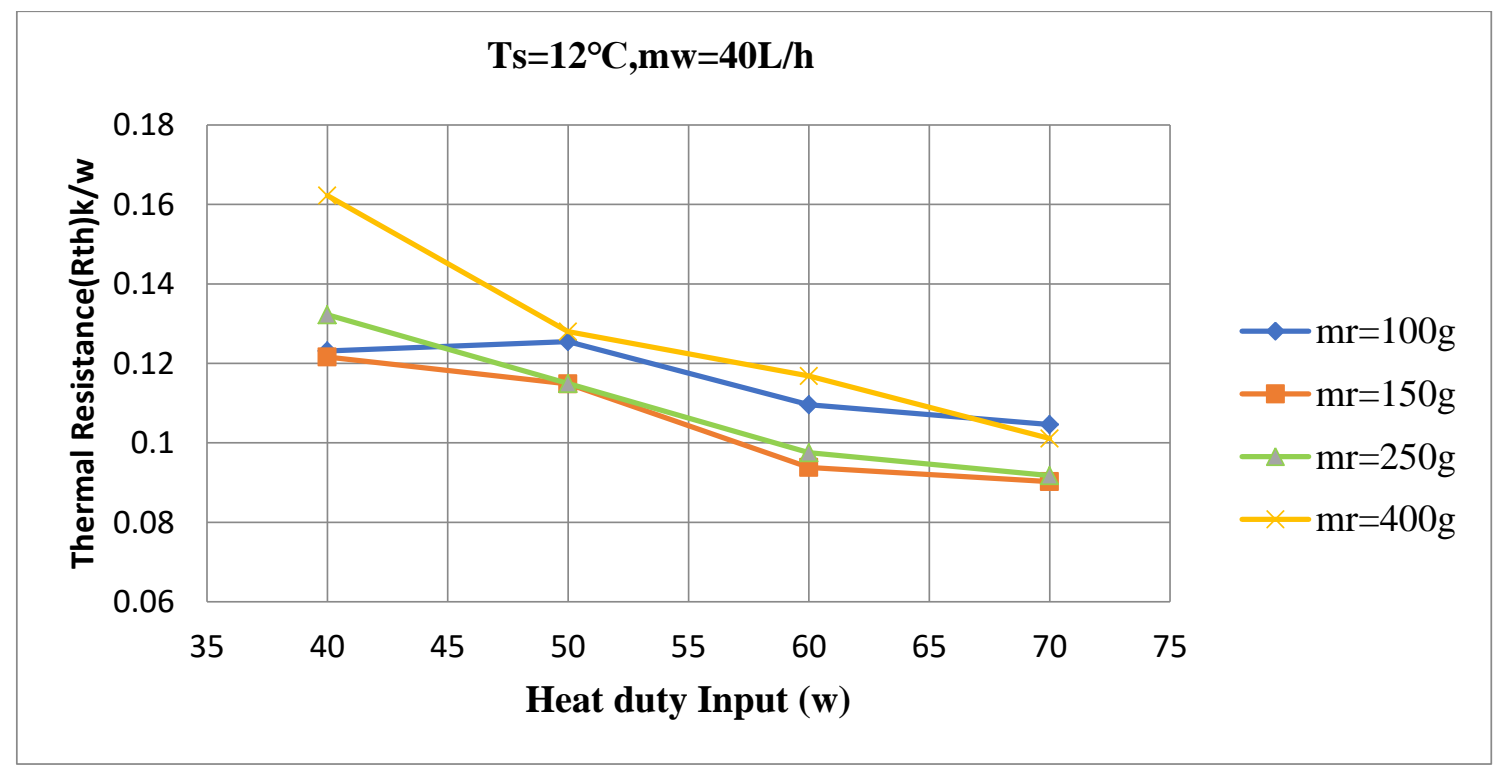

Figure 9: Effect of Input Heat Duty on Thermal Resistance at Different Masses of Working Fluid 


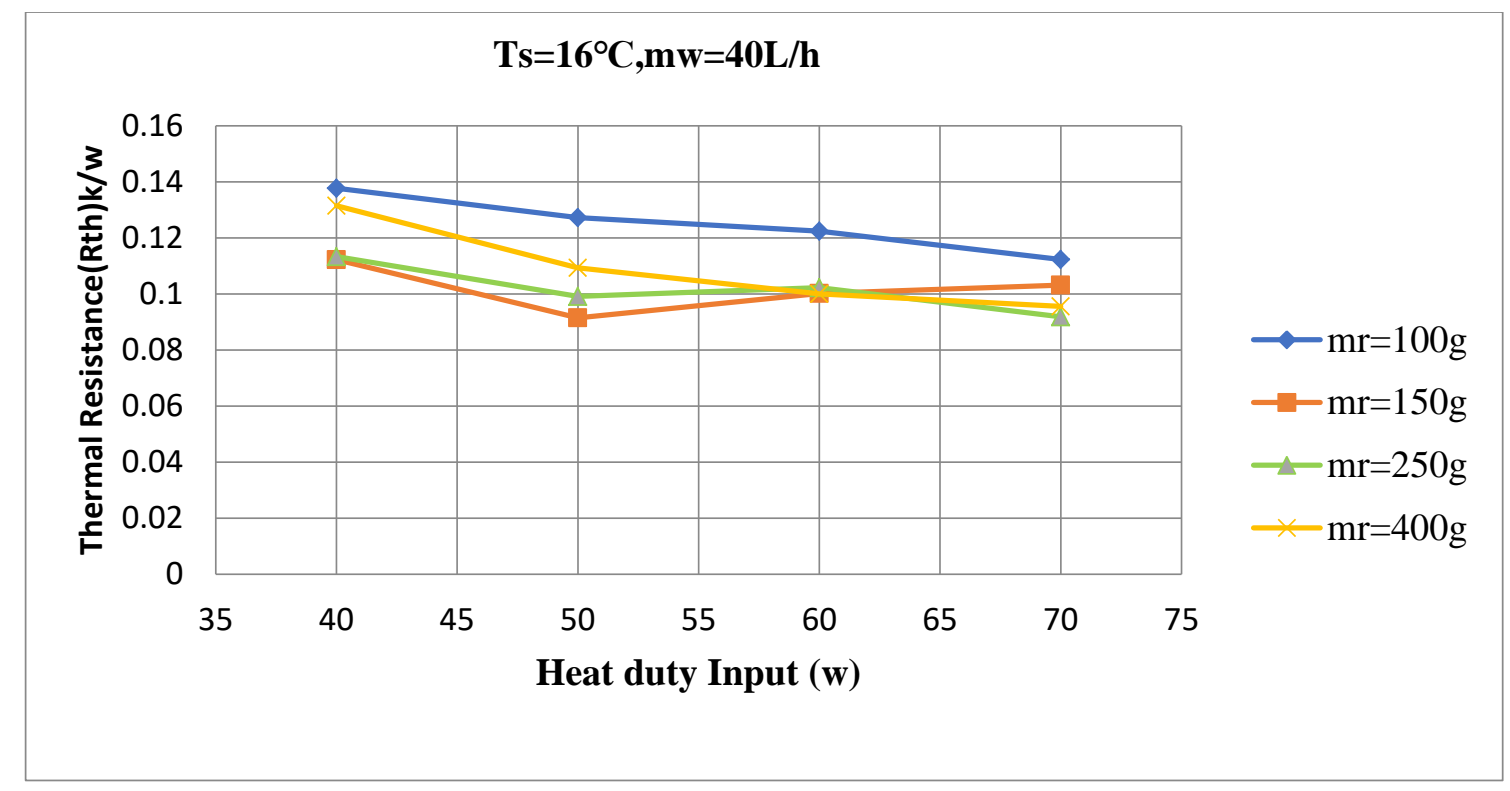

Figure 10: Effect of Input Heat Duty on Thermal Resistance at Different Masses of Working Fluid

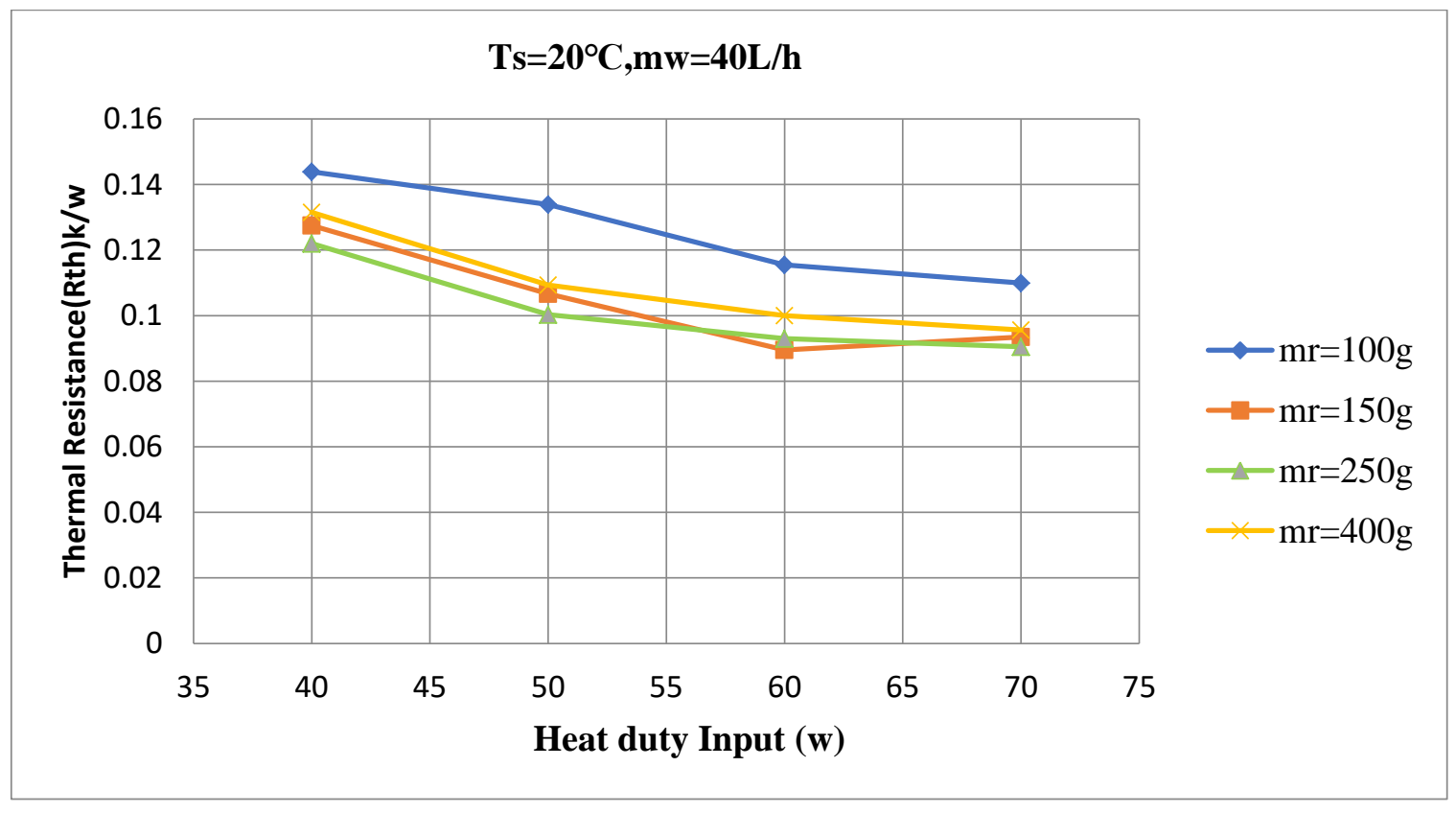

Figure 11: Effect of Input Heat Duty on Thermal Resistance at Different Masses of 134a

\subsection{Effect of Heat Duty Input on Overall Heat Transfer Coefficient}

The relationship between the overall heat transfer coefficient and the heat duty input at constant sink temperature as show in Figures (12) and (13). It is noted from the two figures that the overall heat transfer coefficient starts to increase by increasing the heat duty input and sink temperature, because the temperature gradient begins to increase and the heat pipe performance increases. While the overall heat transfer coefficient for the $\mathrm{mr}=250 \mathrm{~g}$ and $150 \mathrm{~g}$ are greater than the other masses, as shown in Figure (14-15) and (16). Therefore, the heat pipe has the best performance with a mass of R-134a $=150-250 \mathrm{~g}$. Effectiveness of the heat pipe is indirectly brought in terms of thermal resistance and overall heat transfer coefficient. 


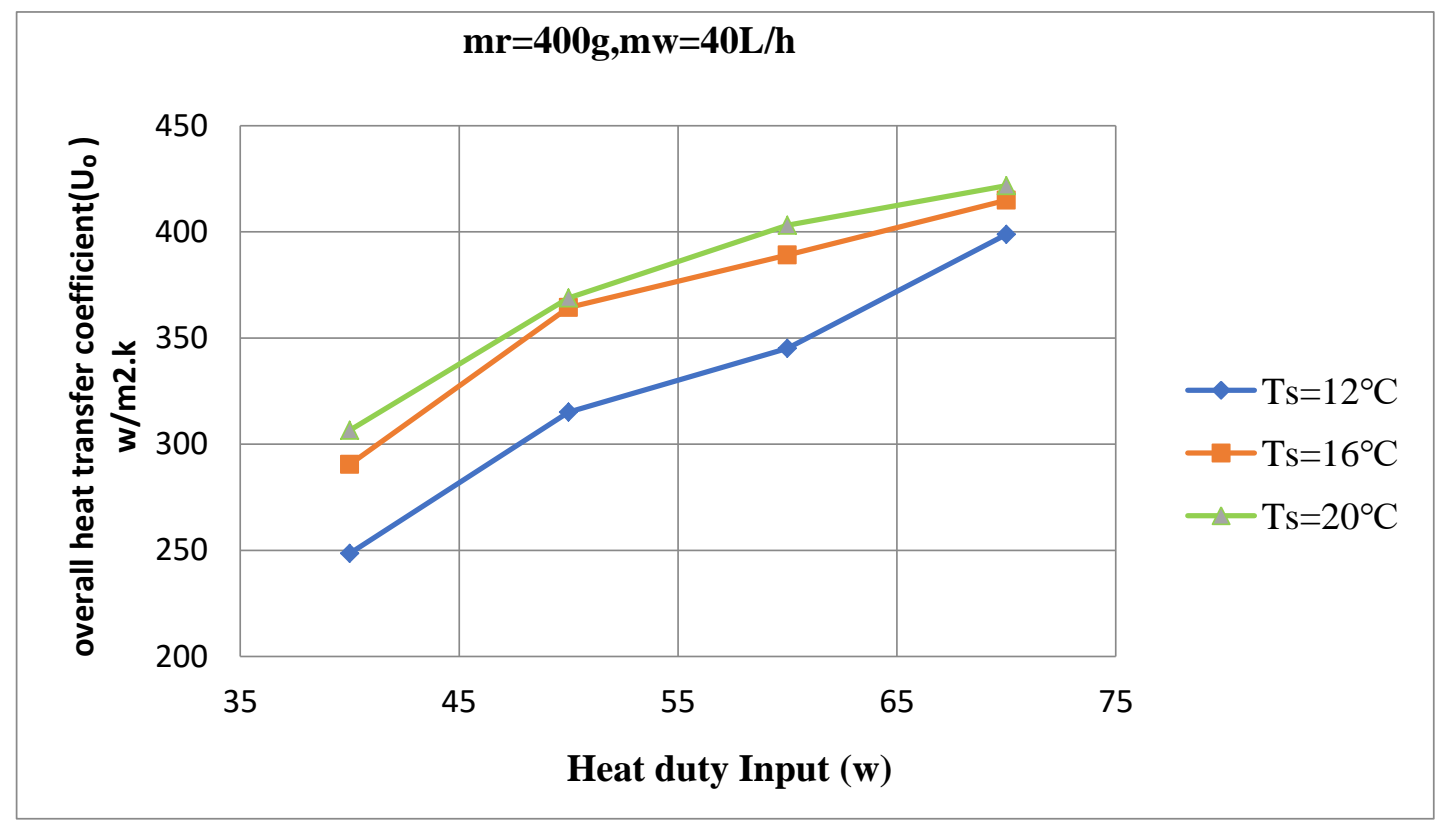

Figure 12: Effect of Input Heat Duty on Overall Heat Transfer Coefficient at Different Sink Temperatures at Mass 134a $=400 \mathrm{~g}$

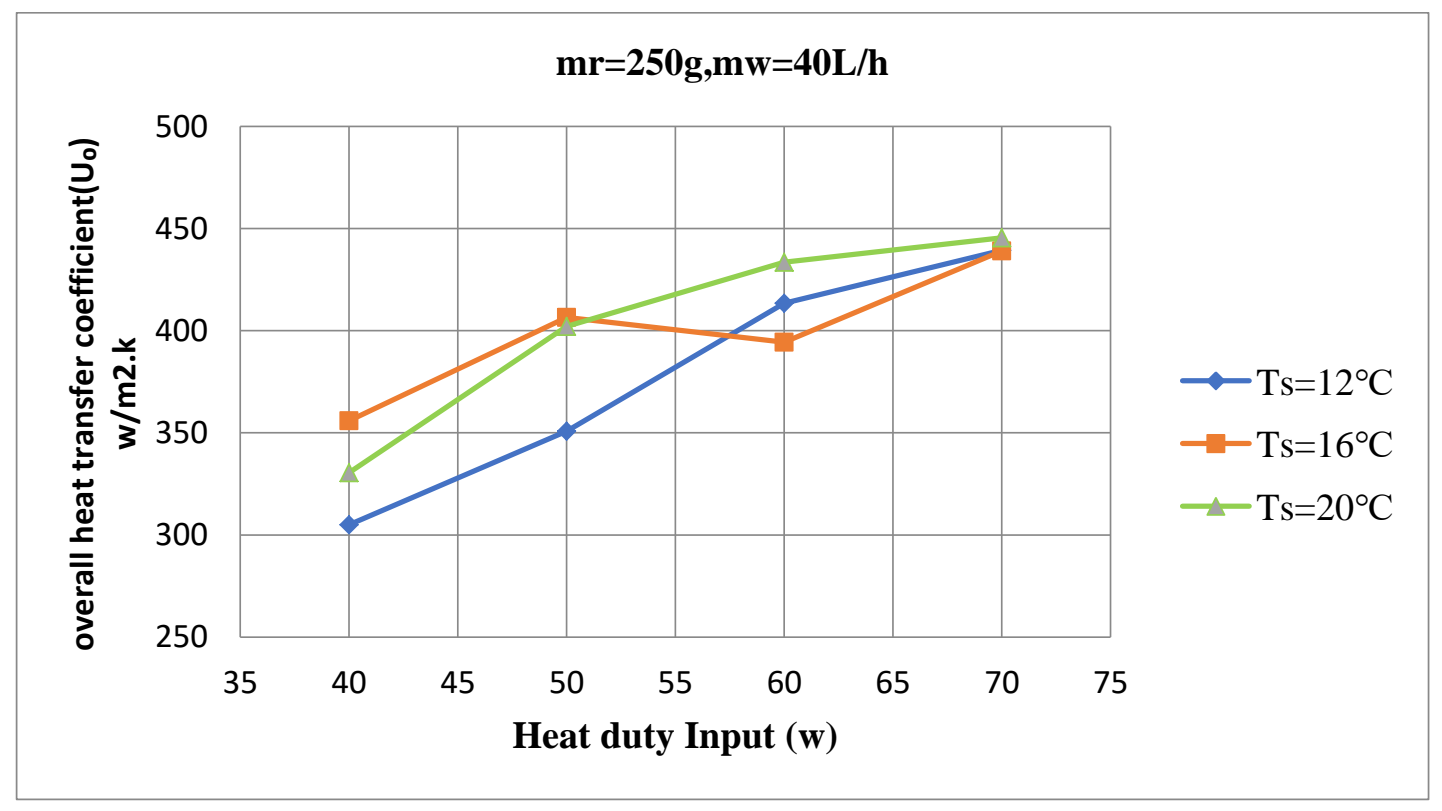

Figure 13: Effect of Input Heat Duty on Overall Heat Transfer Coefficient at Different Sink Temperatures at Mass $134 \mathrm{a}=\mathbf{2 5 0} \mathrm{g}$ 


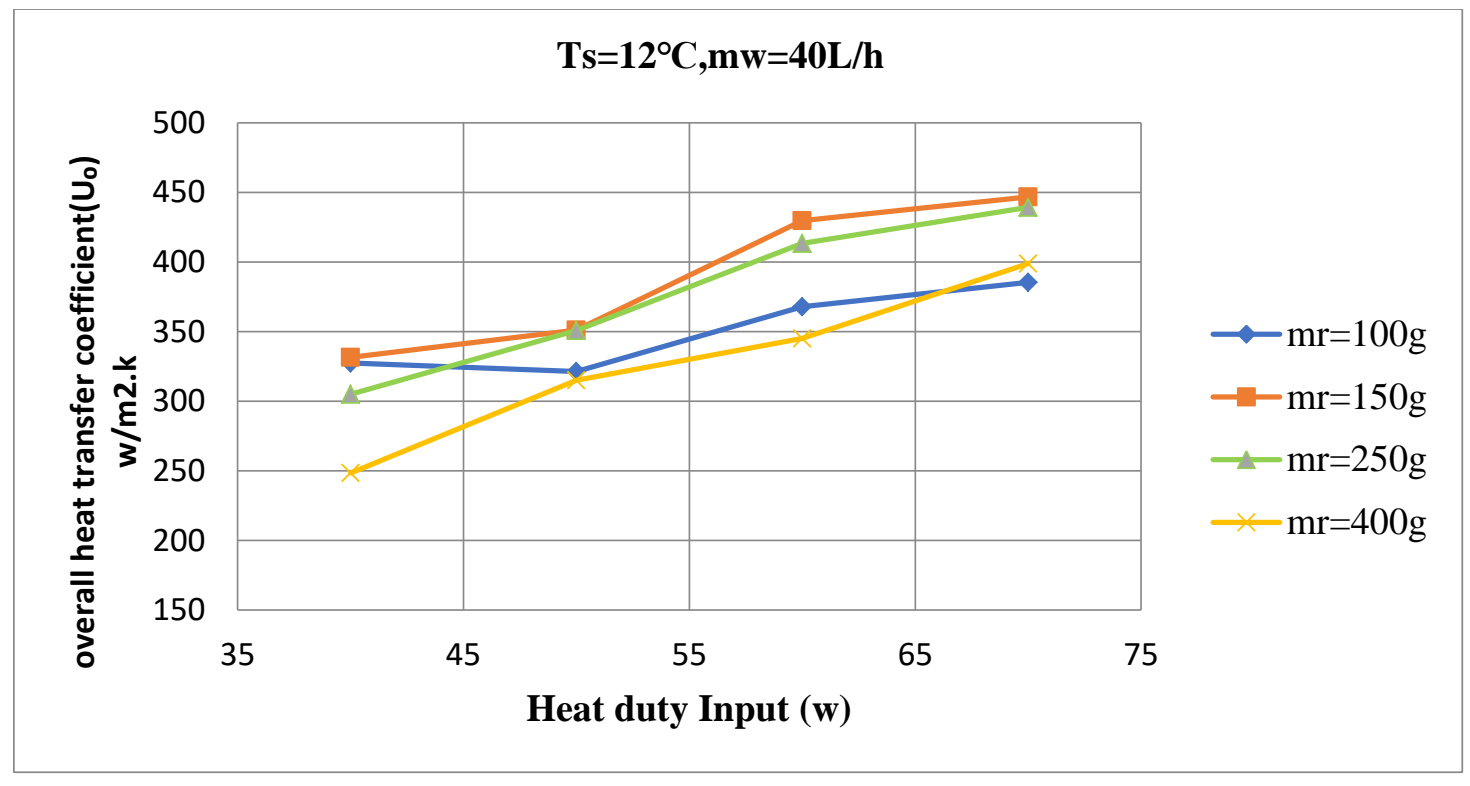

Figure 14: Effect of Input Heat Duty on Overall Heat Transfer Coefficient at Different Masses of 134a

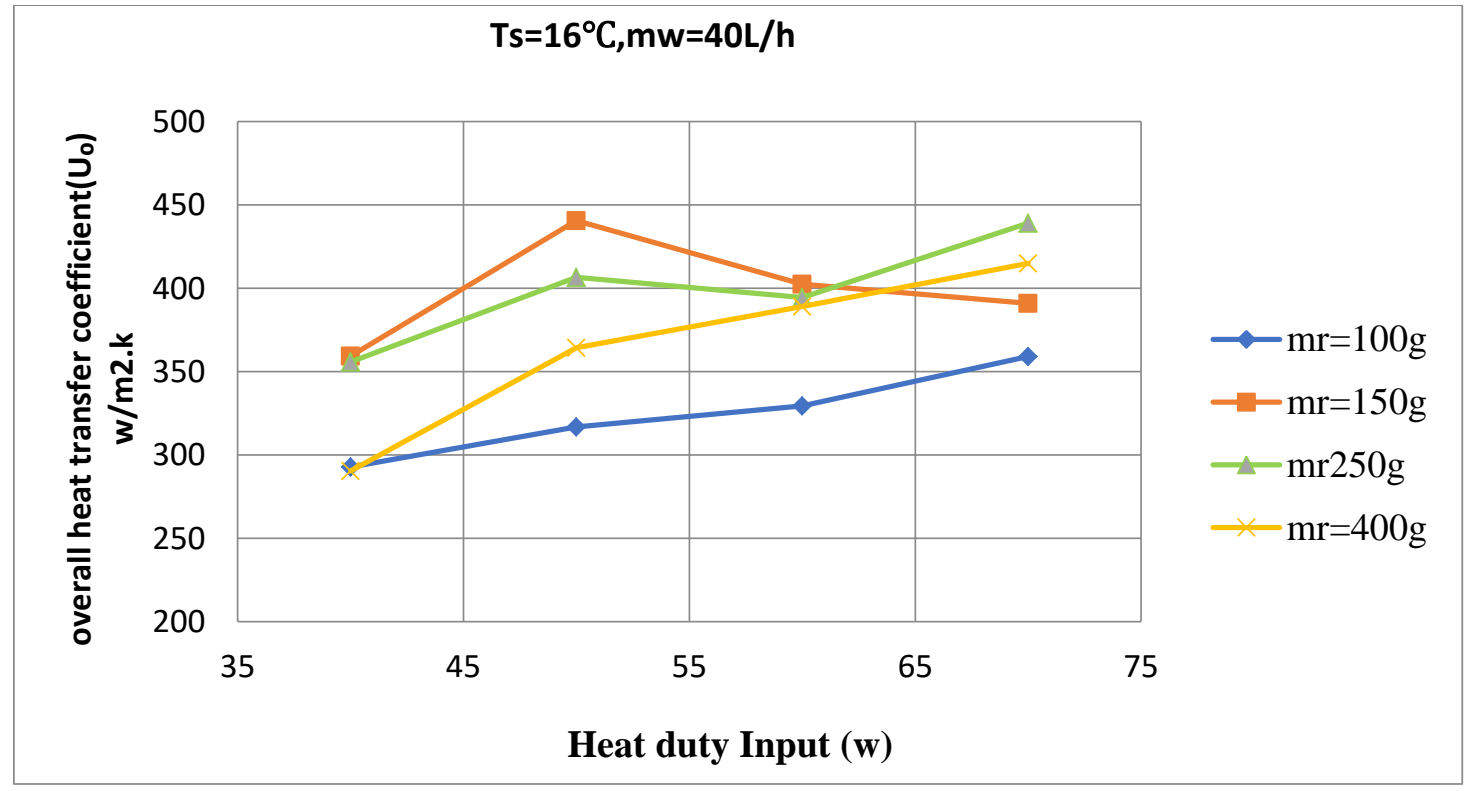

Figure 15: Effect of Input Heat Duty on Overall Heat Transfer Coefficient at Different Masses of 134a 


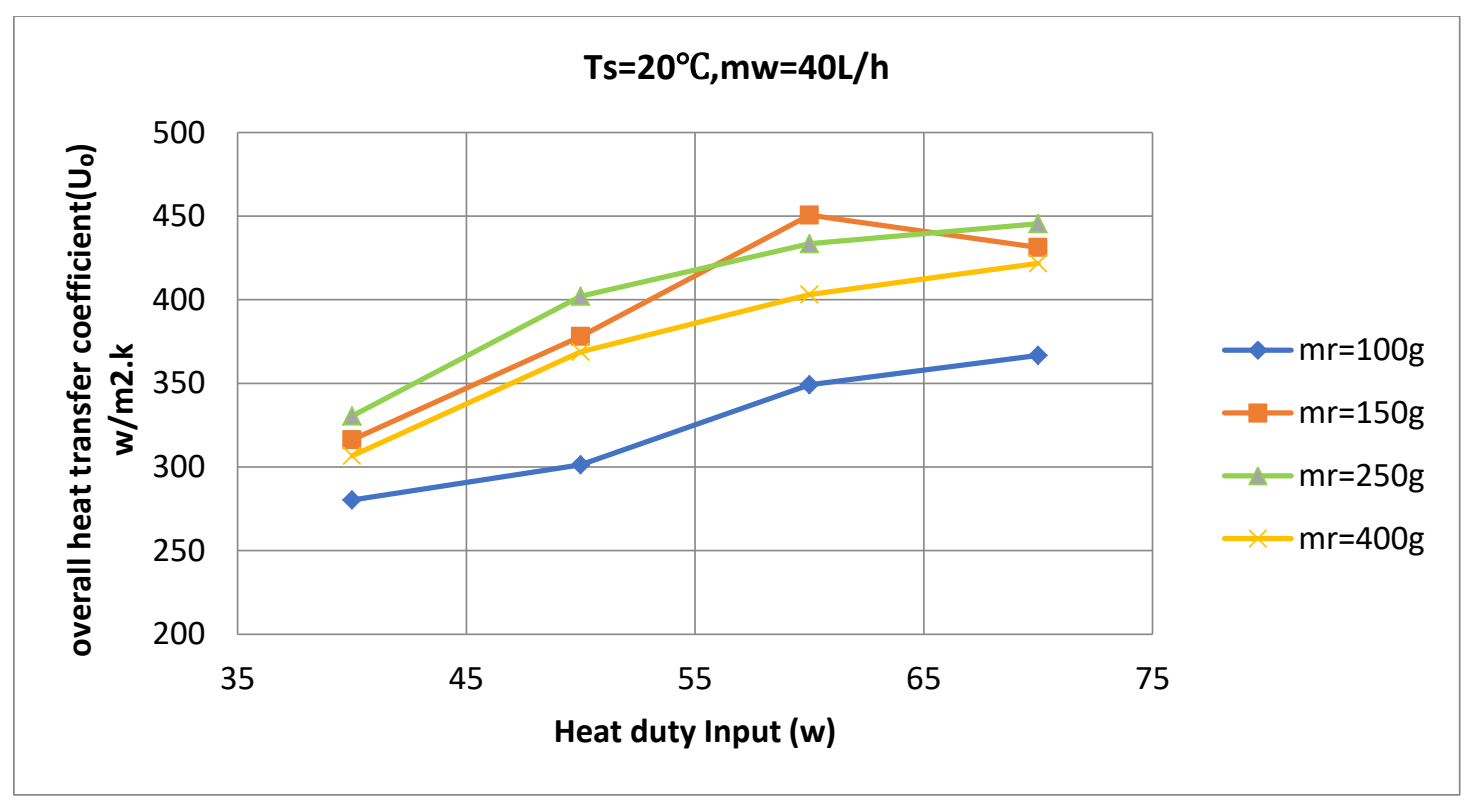

Figure 16: Effect of Input Heat Duty on Overall Heat Transfer Coefficient at Different Masses of 134a

\section{Conclusions:}

In present work the thermal performance of an R134a-filled heat pipe subjected to low heat duty inputs from 40 to 70 watts was investigated. The effects of input heat duty, fill ratio and sink temperature on thermal performance are determined successfully. The heat transfer resistance of the heat pipe has shown that the filling ratio and the sump temperature have an effect on the thermal performance. The unordinary behavior of heat transfer performance with various heat duty, refrigerant mass and sink temperature is observed significantly. The general conclusion is that as the heat duty applied to the evaporator increases, the thermal resistance decreases while the total heat coefficient of the heat pipe increases. . The heater power (P), Ts and R134a mass are affected directly on the migration mechanism and direction and so is the thermal resistance non uniform trend is presented. For $100 \mathrm{~g}$, the thermal resistance is reduced by reducing Ts while the other from masses, the Ts $=12^{\circ} \mathrm{C}$ is the more resistance then $\mathrm{Ts}=20^{\circ} \mathrm{C}$ with non- ordinary behavior of $\mathrm{Ts}=16^{\circ} \mathrm{C}$. The low R134a mass promotes high rate of circulation and the free collusions between the vapor bubbles and condensate droplets. For high masses, the non-uniform trend depends upon the behavior of bubble behavior in continuous phase, the bubbles would turn into the tangential direction by increasing of condensation rate because of the rising of viscosity of liquid phase, the bubbles would be divided into fragments within the continuous phases due to momentum action .The overall heat transfer coefficient has reverse behavior to thermal resistance. The overall heat transfer coefficient is increased by reducing Ts while the other From masses, the Ts $=12^{\circ} \mathrm{C}$ is the less Uo then Ts $=20^{\circ} \mathrm{C}$ with non- ordinary behavior of Ts $=16^{\circ} \mathrm{C}$. The maximum value is observed when $250 \mathrm{~g}$ of $\mathrm{R} 134 \mathrm{a}$ is used which the value of $506 \mathrm{~W} / \mathrm{m}^{2} . \mathrm{K}$ is observed at $\mathrm{P}=70$ $\mathrm{W}$ and $\mathrm{Ts}=12{ }^{\circ} \mathrm{C}$. The R134a mass of $250 \mathrm{~g}$ is considered as critical point for thermal resistance and the overall heat transfer coefficient.

\section{Nomenclature:}

$Q_{c} \quad$ Rejected heat in the condenser

W

$m_{w} \quad$ Mass flow rate of water in condenser cooler $\quad \mathrm{kg} / \mathrm{sec}$

$\mathrm{cp}_{\mathrm{w}}$ Specific heat of water

$\mathrm{T}_{\text {wo }}$ Outlet water temperature from the condenser 
$\mathrm{T}_{\text {wi }} \quad$ Inlet water temperature to the condenser $\quad{ }^{\circ} \mathrm{C}$

$\mathrm{Q}_{\mathrm{e}}$ Heat transfer from evaporator W

$\mathrm{Q}_{\mathrm{E}}$ Input heat to evaporator $\quad \mathrm{W}$

$\mathrm{Q}_{\mathrm{S}} \quad$ Heat transfer to surroundings $\quad$ W

$R_{t h}$ thermal resistance $\quad{ }^{\circ} \mathrm{C} / W$

$T_{e}$ Evaporator mean temperature $\quad{ }^{\circ} \mathrm{C}$

$T_{c}$ Condenser mean temperature $\quad{ }^{\circ} \mathrm{C}$

\section{REFERNCES}

1-ADEL.K.A.E.H. ,2013” Modeling of Transient Response of the Wickless Heat Pipes" D.Tech thesis in Heat duty Engineering in the Faculty of Engineering, AlAzhar U

2- Majid H. Majeed, Ahmad Q. Mohammad and Basil Noori Abed, Experimental Study of Heat Pipe Operating withR-134a, Global Journal of Engineering Research and Technology.ISSN2 249-3107Volume3, Number| (2013),p p.9-16

3- Majid H. Majeed and Osamah Raad Skheel, EXPERIMENTAL STUDY OF WICK STRUCTURE MATERIAL AND SCREEN MESH ON HEAT PIPE PERFORMANCE, The Iraqi Journal For Mechanical And Material Engineering, Vol.16, No4, 2016.

4- Majid H. Majeed, Salah I Najem, Dhafeer M. AL-Shamkhi, Experimental Study Of the Effect Of Working Fluid Quantity On Performance Of Constant Conductance Heat Pipe, journal Wulfenia, Vol 20, No. 3;Mar 2013

5- Amer I. Ismael And Majid H. Majeed, Experimental Study of Effect the Load Applied and Length of Adiabatic Section on the Performance of the Wicked Horizontal Heat Pipe, IOSR Journal of Mechanical and Civil Engineering (IOSRJMCE). Volume 15, Issue 2 Ver. IV (Mar. - Apr. 2018), PP 15-22.

6- Basil N. Merzha, Majid H. Majeed, Fouad A. Saleh, Experimental study of flat plate solar collector performance with twisted heat pipe, 2nd International Conference on Sustainable Engineering Techniques (ICSET 2019)

7-K.S. Ong, Md.Haider-E-Alahi.Performance of R-134a-filled thermosyphon, , Applied Thermal Engineering,23(2003) 2373-2381.

8-Grzegorz Gorecki, Investigation of two-phase thermosyphon performance filled with modern HFC refrigerants, Heat and Mass Transfer (2018) 54:2131-2143.

9- Thanaphol Sukchana, Chaiyun Jaiboonma, Effect of Filling Ratios and Adiabatic Length on Thermal Efficiency of Long Heat Pipe Filled with R-134a, Energy Procedia 34 (2013) 298 - 306.

10- Abdelrahim Abusaf, and Aysar Yasin, Effect of Pressure on the Performance of Passive Two-Phase Closed Thermosyphon System Using R-134a, JOURNAL OF 
ENGINEERING RESEARCH AND TECHNOLOGY, VOLUME 7, ISSUE 1, April 2020. 